\title{
Preserving fertility in patients undergoing treatment for breast cancer: current perspectives
}

\author{
This article was published in the following Dove Press journal: \\ Breast Cancer: Targets and Therapy \\ 17 July 2014 \\ Number of times this article has been viewed
}

\author{
Rebecca Moffat \\ Uwe Güth ${ }^{2}$ \\ 'Women's Hospital, Clinic for \\ Gynecologic Endocrinology and \\ Reproductive Medicine, University \\ Hospital Basel, Basel, ${ }^{2}$ Department \\ of Gynecology and Obstetrics, \\ Breast Center, SenoSuisse, Cantonal \\ Hospital Winterthur, Winterthur, \\ Switzerland
}

\begin{abstract}
Invasive breast cancer (BC) is the most frequent cancer of young women. Considering the trend toward postponing childbearing until the later reproductive years, the number of childless women at diagnosis of BC will continue to increase. The American Society of Clinical Oncology and the American Society for Reproductive Medicine have recommended that the impact of cancer treatments on fertility should be addressed with all cancer patients of reproductive age and that options for fertility preservation, such as cryopreservation of embryos and oocytes, ovarian tissue, in vitro maturation of immature oocytes, and ovarian suppression with gonadotropin-releasing hormone analogs, should be discussed routinely. To optimally counsel patients on how to best weigh the risks and benefits of fertility preservation, both the health care provider and the patient must know about the options, their risks, and their likelihood of success. The aim of this review is to summarize current knowledge on fertility preservation options for young BC patients, surrogates of ovarian function, psychosocial aspects of infertility after cancer treatment, women's attitudes towards childbearing after cancer treatment, and health care providers' attitudes towards fertility preservation.
\end{abstract}

Keywords: breast cancer, fertility preservation, oncofertility, chemotherapy

\section{Introduction}

In 2014, an estimated one in 53 women under the age of 50 years will develop invasive breast cancer $(\mathrm{BC})$. Invasive $\mathrm{BC}$ is the most frequent cancer of young women and the leading cause of cancer death in the 20-39-year age group. ${ }^{1}$ Women under 40 years comprise about $5 \%$ of the overall BC population, ${ }^{2}$ and many of them have not completed childbearing at the time of diagnosis of BC. Birth rates for women younger than 40 years have been declining, whereas the rates continue to rise for women aged 40 through 44 years, and have remained unchanged among women aged 45 years and older. ${ }^{3}$ Considering the trend toward postponing childbearing until the late reproductive years, the number of childless women at diagnosis of BC will continue to increase. In a recent US survey, $77 \%$ of childless women intended to have a child in the future. ${ }^{4}$ In another survey, $75 \%$ of young cancer survivors without children stated they wanted to have children in the future and almost a third of the survivors who already had at least one child wanted to have another. ${ }^{5}$

Mortality rates for $\mathrm{BC}$ have steadily decreased in women since the mid 80 s of the last century, ${ }^{6}$ but treatment for BC will render many affected women under 40 years infertile. Women without children are particularly distressed about their impaired family planning prospects. ${ }^{7}$ Therefore, fertility after treatment for BC and preservation of fertility at diagnosis are issues that are currently receiving significant attention. 
The American Society of Clinical Oncology and the American Society for Reproductive Medicine have recommended that the impact of cancer treatment on fertility should be discussed with all cancer patients of reproductive age and that options for fertility preservation, such as cryopreservation of embryos, oocytes, and ovarian tissue, in vitro maturation of immature oocytes, and ovarian suppression with gonadotropin-releasing hormone $(\mathrm{GnRH})$ analogs should be discussed routinely. ${ }^{8,9}$ Large cancer centers have followed these recommendations, and today many cancer patients in Europe and the USA have access to reproductive medicine. ${ }^{10}$ According to registries of fertility centers performing fertility preservation (FP) consultations and treatments in Europe and the USA, the largest group of young women counseled for cancer therapy-related FP were patients with BC, followed by women diagnosed with lymphoma. ${ }^{11}$

In spite of the encouraging results regarding long-term survival, many oncologists remain reluctant to encourage young BC patients in their desire to have children. ${ }^{12}$ Fear of recurrence in women with hormone-sensitive cancer remains an important barrier to $\mathrm{FP},{ }^{10}$ although pregnancy does not worsen the prognosis of BC survivors. ${ }^{13} \mathrm{~A}$ meta-analysis of several large case series actually showed a decreased risk of dying from $\mathrm{BC}$ in women who became pregnant after BC treatment. ${ }^{14}$ These data might be biased by the fact that women with a good prognosis are more likely to conceive than those with a poor prognosis (ie, the "healthy mother effect"). ${ }^{15}$ On the other hand, pregnancy after BC might have an unknown protective effect. ${ }^{16}$ As $\mathrm{BC}$ tends to recur within the first 2 years, young BC patients are advised to wait at least 2 years before considering pregnancy. ${ }^{16}$ To optimally counsel patients on how to best weigh risks and benefits of FP, both the health care provider and the patient must know about the options and risks of FP and the likelihood of their success. FP is a fast developing field, with many publications contributing to the growing body of evidence, making it challenging to keep up to date. The aim of this review is to summarize current knowledge about the impact of age on fertility, surrogates of ovarian function, psychosocial aspects of infertility after cancer treatment, FP options for young BC patients, women's attitudes towards childbearing after cancer treatment, and health care providers' attitudes towards FP.

\section{Materials and methods}

Peer-reviewed journals were searched in PubMed starting in November 2013 using the terms "breast cancer" and "fertility OR childbearing OR assisted reproduction" in all fields and the filters "publication date $=5$ years" and "species $=$ human". Suitable for inclusion were original articles from peer-reviewed journals and statistical reports published in English. Additional publications cited in the identified papers were retrieved manually. Studies were screened based on title and abstract. The main search was completed by RM. Titles, abstracts, and full text articles were screened by both authors. The selection criteria were aimed at covering the range of issues within the topic of this review.

\section{Age-related decline of fertility in healthy women}

The goal of FP is for the woman to be able to give birth to a healthy baby after gonadotoxic therapy. In the course of counseling before FP treatment, the patient should receive information on her options regarding FP, along with the risks and success rates. Unfortunately, there is a lack of knowledge about live birth rates in $\mathrm{BC}$ patients after cancer treatment. Information concerning live birth rates after FP therefore falls back on data collected from women undergoing assisted reproduction for infertility. The 1992 Fertility Clinic Success Rate and Certification Act mandates that all US clinics offering assisted reproductive technologies (ART) annually report success rates to the Centers of Disease Control and Prevention, ${ }^{17}$ thus providing a rich source of information about the factors that contribute to success, ie, the delivery of a live baby. A woman's ability to conceive ends long before the last menstrual period (menopause). The median age for menopause in most Western countries is between 50 and 52 years. Fecundity starts decreasing gradually at the age of 32 years, rapidly after age 37 years, and dramatically after 40 years of age. ${ }^{18}$ The spontaneous conception rate is less than $2 \%$ at age 42 years and is just about $0 \%$ at 45 years. ${ }^{19}$ Likewise, age impacts significantly on the success of ART. Table 1 summarizes the success rates of 151,923 in vitro fertilization (IVF) cycles performed during 2011 in the USA. Live births are less likely to occur in older women and they are at higher risk for miscarriage. ${ }^{20}$ There is a widespread misperception among the general public and among non-infertility specialist clinicians that ART can reverse the age-related decline of fertility. ${ }^{21}$

\section{Surrogates of ovarian function and female fertility}

Amenorrhea (absence of menstruation) is triggered by the number of oocytes falling below a threshold number and evidently is a clinical surrogate for permanent loss of ovarian function. ${ }^{22}$ However, the number of follicles 
Table I Success with assisted reproductive technologies in the USA in 2011

\begin{tabular}{llll}
\hline $\begin{array}{l}\text { Age } \\
\text { group, } \\
\text { years }\end{array}$ & $\begin{array}{l}\text { Percentage } \\
\text { of IVF cycles } \\
\text { using nondonor } \\
\text { eggs resulting } \\
\text { in pregnancy }\end{array}$ & $\begin{array}{l}\text { Percentage } \\
\text { of IVF cycles } \\
\text { using nondonor } \\
\text { eggs resulting } \\
\text { in live birth }\end{array}$ & $\begin{array}{l}\text { Percentage } \\
\text { of transfers of } \\
\text { frozen embryos } \\
\text { resulting in live } \\
\text { birth }\end{array}$ \\
\hline$<35$ years & 46.1 & 40.0 & 39.0 \\
$35-37$ years & 38.5 & 31.9 & 35.5 \\
38-40 years & 29.2 & 21.5 & 29.7 \\
$41-42$ years & 19.4 & 12.1 & 24.0 \\
$43-44$ years & 10.7 & 5.3 & 17.0 \\
$>44$ years & 4.1 & 1.1 & 14.8 \\
\hline
\end{tabular}

Note: Success rates are based on 151,923 cycles. ${ }^{20}$

Abbreviation: IVF, in vitro fertilization.

(ovarian reserve) varies widely between women of the same age. Ovarian reserve tests include basal folliclestimulating hormone measured in the early follicular phase of the menstrual cycle, inhibin B, antral follicle count, and ovarian volume assessed by transvaginal ultrasound, and anti-Müllerian hormone (AMH). Among the various tests of ovarian reserve, antral follicle count and $\mathrm{AMH}$ are considered to be the most accurate. ${ }^{23,24} \mathrm{~A}$ further advantage of $\mathrm{AMH}$ is that it can be measured at any point in the menstrual cycle. ${ }^{25}$ However, depending on the type of assay, AMH may not be stable under certain storage or assay conditions. Prolonged storage of samples at room temperature and predilution of serum increases AMH levels in the sample, causing poor reproducibility. ${ }^{26}$ Gonadotoxic therapy reduces AMH levels, and women with a lower pretreatment $\mathrm{AMH}$ are more likely to develop amenorrhea after chemotherapy for early BC. Thus, measurement of AMH pretreatment may guide clinicians and women in treatment decisions and whether or not to consider FP strategies prior to $\mathrm{BC}$ treatment. ${ }^{27}$ Amenorrhea and $\mathrm{AMH}$ are preferred surrogates in analyzing the effect of gonadotoxic therapy on ovarian reserve. Unfortunately, AMH neither predicts spontaneous conception of a pregnancy ${ }^{28}$ nor pregnancy or live birth after IVF, ${ }^{29}$ and amenorrhea denotes the permanent loss of ovarian function. However, permanent loss of fertility arises long before amenorrhea, rendering these popular surrogates misleading because they are not helpful in predicting fertility after cancer treatment.

\section{Impact of BC therapy on fertility}

The ovary contains a nonproliferating fixed number of oocytes with which a woman is born and that are not replenished. Primordial follicles containing the oocytes develop into primary follicles and then into secondary follicles independently of follicle-stimulating hormone.
Once a follicle reaches the antral stage, the surrounding proliferating granulosa cells require follicle-stimulating hormone for further development. BC treatment affects fertility in a number of ways. Gonadotoxic chemotherapy adversely affects ovarian function depending on age and type of chemotherapy received, ${ }^{30,31}$ but comprehensive understanding of the effects of chemotherapy on the ovary and the follicular pool is less abundant. ${ }^{32,33}$ Alkylating agents are particularly harmful because they can destroy oocytes permanently. All chemotherapeutics are capable of damaging developing follicles, resulting in temporary amenorrhea because their granulosa cells are proliferating. If the primordial follicle pool remains undamaged, menses will return, with the development of new follicles within 3-6 months after the last treatment cycle. Table 2 summarizes the effects of chemotherapeutic agents on the follicular pool of the ovary. ${ }^{34,35}$ Apart from the direct gonadotoxic effects of chemotherapy, endocrine therapy, which is recommended for at least 5 years to reduce the risk of recurrence in women with estrogen receptor-positive $\mathrm{BC},{ }^{36}$ indirectly affects fertility as well, because during this time there would be a natural age-related decline of fertility. Even if women are neither treated with chemotherapy nor endocrine therapy, they will be counseled by most oncologists to wait at least 2 years before considering pregnancy, ie, a time interval that will render at least some of the women permanently infertile due to the age-related decline of fertility.

\section{Psychosocial aspects of infertility and FP}

$\mathrm{BC}$ is the most frequent malignancy in women of reproductive age. In particular, women younger than 35 years are more likely to present with a higher grade, more extensively proliferating, and vessel invading $\mathrm{BC},{ }^{37}$ and are more prone to receive chemotherapy to reduce the risk of recurrence. According to several surveys, the majority of young childless

Table 2 Effect of chemotherapy on ovarian follicles 34,35

\begin{tabular}{lll}
\hline $\begin{array}{l}\text { Chemotherapeutic } \\
\text { agent }\end{array}$ & Toxic effect & Result \\
\hline $\begin{array}{l}\text { Alkylating agents, } \\
\text { topoisomerase } \\
\text { inhibitors }\end{array}$ & $\begin{array}{l}\text { Apoptotic cell death via } \\
\text { induction of breaks in } \\
\text { double-stranded DNA }\end{array}$ & $\begin{array}{l}\text { Diminution of ovarian } \\
\text { reserve }\end{array}$ \\
Antimetabolites & $\begin{array}{l}\text { Damage of proliferating } \\
\text { granulosa cells }\end{array}$ & $\begin{array}{l}\text { Transient amenorrhea, } \\
\text { no alteration of } \\
\text { ovarian reserve }\end{array}$ \\
& & \\
Taxanes & Uncertain & Uncertain \\
\hline
\end{tabular}


cancer survivors want to have children in the future. ${ }^{5,11,38,39}$ Loss of reproductive potential after cancer treatment severely reduces quality of life in young survivors, and might even be more stressful than the cancer diagnosis itself. However, cancer survivors tend to be more concerned about the health risks in their offspring. ${ }^{40}$ In a web-based survey, almost a third of young BC patients stated that loss of fertility impacted their treatment decisions. BC patients with greater concerns about future infertility required a higher reduction of risk of recurrence from chemotherapy. ${ }^{39}$ Apart from loss of fertility, young $\mathrm{BC}$ patients are also concerned about entering menopause with $\mathrm{BC}$ treatment, and tend to overestimate their risk of becoming postmenopausal. ${ }^{39}$ Women counseled about their risk of infertility from cancer therapy by both an oncology team and a fertility specialist had significantly less regret about their decision to preserve fertility than those counseled only by an oncology team. Receiving counseling from a fertility specialist and preserving fertility both appear to decrease regret and were associated with improvement in quality of life after cancer treatment. ${ }^{41}$ Ideally, young BC patients should be referred to a specialist in the field of FP at the time of their cancer diagnosis and prior to initiation of treatment. ${ }^{42}$ Counseling a patient about her options for FP in a timely and supportive manner is challenging and requires adequate knowledge and sufficient communication skills. ${ }^{43}$ Web-based or printed decision aids containing information about BC, the effect of cancer treatment on female fertility, options for FP, and their risks seem to reduce decisional conflict and regret about fertility-related treatment options in young $\mathrm{BC}$ patients. Women using a decision aid were usually more satisfied with their decision, had improved fertilityrelated knowledge, were more satisfied with the information received, and considered the aid helpful. ${ }^{44,45}$

\section{Methods for FP in premenopausal BC patients}

Ovarian stimulation and cryopreservation of embryos yields the highest live birth rate and is considered the best established option for FP in young BC patients. ${ }^{34,46}$ Alternatively, women who do not have a partner or are not willing to use donor sperm can freeze their oocytes without fertilizing them. ${ }^{47,48}$ Cryopreservation of ovarian tissue, in vitro maturation of immature oocytes, and ovarian suppression with GnRH analogs are still considered experimental. ${ }^{46,49,50}$ No matter what method of FP is chosen, there is a dramatic lack of data on success rates of FP in patients with $\mathrm{BC}$ or other types of cancer. One single study focusing on the long-term outcome of FP and based on a small number of patients (of which more than half were BC patients) reported very low utilization of frozen embryos after FP. ${ }^{51} \mathrm{BC}$ patients who want to preserve their fertility should be referred by their oncologist to a fertility specialist at diagnosis and preferably before or very shortly after surgery in order to decrease the time delay and increase the number of women who can feasibly undergo FP. ${ }^{52}$ On the other hand, institutions offering FP services should be able to provide rapid access to FP counseling by an interdisciplinary medical team consisting of oncologists, reproductive endocrinologists, and reproductive surgeons. ${ }^{53}$ Patients facing fertility-threatening treatments might also need additional help from mental health professionals during a difficult decision-making process ${ }^{43}$ and from financial counselors for tackling the high costs if medical insurance coverage is lacking. ${ }^{54}$ Genetic counseling is recommended for young $\mathrm{BC}$ patients carrying the breast cancer susceptility genes $B R C A 1$ or $B R C A 2$ to discuss the potential risks of transmission to their offspring and the possibility of preimplantation genetic diagnosis of BRCA mutations in the embryo before embryo transfer. ${ }^{55}$ Apart from firm interdisciplinary collaborations within the medical team, institutions offering FP should be equipped or closely associated with an experienced ART laboratory capable of providing embryo, oocyte, and ovarian tissue cryopreservation. Ideally, the laboratory should be skilled in the vitrification technique for freezing. ${ }^{56}$

Lastly, it is important to emphasize that costs and insurance coverage for $\mathrm{FP}^{57,58}$ and legislation regulating the storage of embryos and gametes vary considerably around the world. ${ }^{59}$

\section{Cryopreservation of mature oocytes and embryos}

Cryopreservation of embryos after emergency IVF requires controlled ovarian stimulation (COS) with gonadotropins and sperm from a partner or a donor, and causes a delay of chemotherapy of at least 2 weeks. ${ }^{52}$ Usually, daily subcutaneous injections of follicle-stimulating hormone \pm luteinizing hormone are administered, starting during menses in the very early follicular phase, although it is possible to start COS randomly during the cycle, as well as during the luteal phase ${ }^{60,61} \mathrm{BC}$ patients will often have time to undergo at least one COS during the interval between surgery and postoperative chemotherapy, ${ }^{62}$ provided that they are referred early. ${ }^{50}$ Patients desiring FP should be informed that emergency IVF is not advisable when neoadjuvant chemotherapy is preferred by the oncology team. ${ }^{63}$ During COS, growth of ovarian follicles is monitored by repeated transvaginal 
ultrasound and measurements of estrogen \pm progesterone in the blood. Before oocyte retrieval, final oocyte maturation is achieved by injecting either human chorionic gonadotropin (hCG) or a GnRH agonist, provided that the patient is under an antagonist protocol. The introduction of the antagonist protocol, in which premature ovulation is suppressed with a $\mathrm{GnRH}$ antagonist, makes it possible to avoid hCG for induction of ovulation by using a $\mathrm{GnRH}$ agonist instead of hCG for final oocyte maturation. ${ }^{64}$ The GnRH agonist displaces the GnRH antagonist from the luteinizing hormone receptor, thereby causing a release of endogenous gonadotropins (so-called "flare-up"). Many studies have shown that using a GnRH agonist instead of hCG for induction of ovulation prevents ovarian hyperstimulation syndrome. ${ }^{65}$ Ovarian hyperstimulation syndrome is the most frequent complication of COS and appears in 3\%-8\% of IVF cycles. ${ }^{66}$ The hallmark of ovarian hyperstimulation syndrome is increased capillary permeability triggered by the release of vasoactive substances secreted by the ovaries under hCG stimulation, resulting in a shift of serum from the intravascular space to the third space (mainly the abdomen). Vascular endothelial growth factor is the principal vasoactive mediator in ovarian hyperstimulation syndrome, and the one most responsible for increased capillary permeability. The consequence of the fluid shift to the third space is hemoconcentration, hypoperfusion, and an increased risk of thromboembolism. ${ }^{67}$ Ovarian hyperstimulation syndrome can delay and complicate cancer treatment. $\mathrm{BC}$ patients present a particular challenge because of COS-related hyperestrogenemia which might have a negative impact on estrogen-sensitive cancer cells. Administering letrozole or tamoxifen during COS minimizes circulating estrogen levels without compromising the quality of oocytes or embryos, although there are no randomized controlled trials supporting the superiority of adding letrozole or tamoxifen compared with standard COS protocols. ${ }^{68}$

Oocytes and embryos can be cryopreserved using either the slow freezing or vitrification technique. In contrast with embryos, unfertilized oocytes are more prone to alterations of the meiotic spindle and damage of DNA integrity during the freezing and thawing process. ${ }^{69}$ The introduction of an ultra-fast freezing protocol (vitrification) that was originally developed for storing donated oocytes avoids crystal formation in the cell and considerably improved survival rates of unfertilized oocytes. ${ }^{70}$ Mainly because the success rates using oocytes that were stored after slow freezing were poor, ${ }^{71}$ cryopreservation of oocytes was considered experimental until 2012. Based on a recent meta-analysis, the live birth rate after oocyte vitrification is comparable with that of fresh embryo transfer. ${ }^{72}$
The chances of transferring frozen-thawed embryos resulting in live birth are primarily dependent on the woman's age at the time of egg retrieval (see Table 1 for the 2011 success rates in the USA) and are lower after frozen embryo transfer than after fresh embryo transfer. Live birth rates summarized in Table 1 appear to be higher after frozen embryo transfer than after fresh embryo transfer in older women. This is due to fact that women undergoing frozen embryo transfer were younger at the time of egg retrieval, thus underlining once again the impact of age on the success of ART.

Interpretation of published success rates in the field of ART can be tricky because most of the data are derived from healthy infertile individuals undergoing IVF or oocyte donation using oocytes of young donors. Fertility centers offering FP counseling should therefore inform the patient about the center-specific pregnancy rates. The risk of a weak response to COS seems to be significantly higher in $\mathrm{BC}$ patients than in patients with other cancers. The reason for the poorer response in $\mathrm{BC}$ patients remains to be elucidated. The use of letrozole during COS and/or a potentially smaller ovarian reserve in BRCA mutation carriers might be the cause of this poor ovarian response. ${ }^{73}$

\section{Cryopreservation of ovarian tissue}

Ovarian tissue cryopreservation (OTC) can be an option for $\mathrm{BC}$ patients under the age of 37 years who cannot delay urgent treatment for cancer, such as neoadjuvant chemotherapy, and whose general state of health permits surgery. ${ }^{74}$ Of note, OTC may add to a further decrease of ovarian reserve and thereby impact on natural fertility after cancer treatment, as shown by multiple studies investigating the effect of conservative ovarian surgery on ovarian reserve..$^{63,75}$

OTC requires laparoscopy or laparotomy for harvesting ovarian cortex containing thousands of primordial follicles and for transplanting the cortical strips after treatment. Orthotopic transplantation is more successful than heterotopic transplantation, and all of the 24 live births reported by May $2013^{76}$ occurred after orthotopic transplantation of ovarian cortical strips to the remaining ovary. To date, heterotopic grafting of ovarian cortex strips has never resulted in a live birth after COS and IVF, and the optimal site of transplantation is still under debate. However, restoration of ovarian function was consistently observed after heterotopic ovarian transplantation, in some cases lasting for 7 years. ${ }^{77}$ One spontaneously conceived live birth was reported after heterotopic transplantation, highlighting the need for caution when interpreting the source of pregnancies in recipients of ovarian cortex with intact ovaries. ${ }^{78}$ 
OTC is not advisable in carriers of the BRCA mutation, given the increased risk for ovarian cancer. ${ }^{79}$ Overall, there are insufficient data on the efficacy, safety, and reproductive outcomes, and OTC remains an experimental FP option that should only be offered to carefully selected patients by centers with the necessary laboratory and surgical expertise. ${ }^{56,80}$

\section{In vitro maturation of immature oocytes}

Patients with estrogen-sensitive BC and those with limited time for FP before cancer treatment may be candidates for this technology, since in vitro maturation omits gonadotropin stimulation or uses only a short course of gonadotropins. It may also be used in combination with other FP methods, such as OTC. ${ }^{81,82}$ In vitro maturation was initially created for the treatment of women with polycystic ovarian syndrome. Caution must be exercised in extrapolating the existent data on in vitro maturation for both efficiency and safety to young cancer patients ${ }^{83,84}$ and should be performed by experienced centers after informing the patient that pregnancy rates are significantly lower with in vitro maturation than with conventional IVF protocols. ${ }^{85}$

\section{Ovarian suppression with $\mathrm{GnRH}$ analogs}

Temporary ovarian suppression using GnRH analogs during adjuvant chemotherapy has been proposed to prevent premature ovarian failure after cytotoxic therapy, but study results are conflicting and the preponderance of evidence indicates that GnRH analogs are ineffective. ${ }^{49}$ Therefore, this FP option is considered experimental, even though ovarian suppression with GnRH analogs would be widely available, relatively inexpensive, and not require COS or invasive surgery. Meta-analysis of the currently available data has not demonstrated the efficacy of GnRH treatment; hence, it is only recommended in the setting of clinical trials. Given the absence of clear evidence of harm, GnRH analogs may be considered outside of a clinical trial setting for young $\mathrm{BC}$ patients who do not have any other option, provided there is careful discussion of the lack of proven benefit. ${ }^{86}$

\section{Childbearing after BC}

A recent web-based survey revealed that more than half of women with early BC stated that they had desired future pregnancy at the time of diagnosis and $10 \%$ actually underwent FP. The majority of the women completing the survey received chemotherapy and most resumed cyclic menses after treatment. However, only a relatively small percentage actually became pregnant. ${ }^{87}$ There is a discrepancy between the wish for and actual use of FP. Although counseling is recommended for all women in the reproductive age group and appears to positively affect quality of life for survivors, only a few patients take the opportunity to preserve their fertility and even fewer actually utilize the preserved gametes. The worldwide utilization rates are very low, ranging from $2 \%$ to $4 \%,{ }^{88}$ indicating that other factors, such as course of the disease, parity, and fear of recurrence might account for this discrepancy. ${ }^{89}$ Two other population-based controlled studies focusing on cancer survivors diagnosed and treated in Canada during the 1990s and in Norway from 1971 to 1997 found that BC survivors who had a history of childbirth prior to a $\mathrm{BC}$ diagnosis had a significant reduction in the rate of childbearing as compared with controls. Considering that childless women at $\mathrm{BC}$ diagnosis had rates of childbirth similar to those of controls, decreased fertility after BC treatment itself cannot be the whole explanation. Possibly women delay or avoid pregnancy for fear of recurrence with the estrogen stimulation of pregnancy, and this effect may be more pronounced in women who already have at least one child. ${ }^{90,91}$ Childless survivors have been found to be more likely to desire future children despite concerns for the mother's or infant's health. ${ }^{5}$ Interviewed 10 years after their cancer diagnosis, childless women seem to be more distressed about their infertility than women who have at least one biological child or have adopted a child. ${ }^{7}$ To date, patients' perceptions of fertility and parenthood after the experience of $\mathrm{BC}$ are still poorly investigated and understood. ${ }^{92}$

\section{Health care providers' knowledge and attitudes regarding $\mathbf{F P}$}

Generally, response rates to surveys regarding selfevaluation of knowledge and attitudes towards FP are low, which could seriously impair the validity and generalizability of results. ${ }^{93}$ Younger ( $<50$ years) and female oncologists, as well as oncologists working in a multidisciplinary center, tend to have a more positive attitude toward FP. ${ }^{94}$ From the oncologist's point of view, the patient's age, whether she has a partner or children, time constraints, estrogen receptor expression, availability of cooperating reproductive specialists, knowledge about FP, and anxiety about delay of chemotherapy or recurrence of disease are commonly mentioned barriers to referral for FP counseling. ${ }^{95}$ A further reason for avoiding referral to fertility counseling is the oncologist's perception that, if patients did not raise the issue themselves, they were not interested. ${ }^{12}$ From the reproductive specialist's point of view, anxiety about treating patients with a hormone-sensitive cancer, fear of recurrence, whether or not the woman has a partner, and insufficient knowledge 
about $\mathrm{BC}$ are the most important barriers to performing $\mathrm{FP} .^{96}$ From the patient's point of view, receiving information about the impact of cancer treatment on fertility was found to be particularly important for younger and childless women, and they preferred to receive information in an individual consultation. ${ }^{97}$ Psychological stress, time pressure, fear of delaying cancer treatment, and costs are the main factors influencing the patient's decision to proceed with FP. ${ }^{98,99}$

Since the early 1990s, the prevalence of FP counseling by oncologists has been steadily growing, with recent studies reporting rates of $60 \%-70 \%,{ }^{100}$ and in the past 10 years, the trend towards early referral to fertility specialists for FP has been increasing. ${ }^{101}$ Nevertheless, women who are childless, younger, Caucasian, heterosexual, and who have graduated from college seem to have better and more frequent access to FP counseling and FP than women from other socioeconomic backgrounds, according to a survey conducted in the USA. ${ }^{102}$

\section{Conclusion}

The majority of $\mathrm{BC}$ patients are treated by chemotherapy and long-lasting endocrine therapy, rendering many infertile due to gonadotoxic and natural age-related effects on ovarian function. The most successful techniques for FP in BC patients are cryopreservation of oocytes and embryos. Success rates are largely dependent on the patient's age at the time of oocyte retrieval. Ovarian suppression with $\mathrm{GnRH}$ analogs, in vitro maturation of immature oocytes, and cryopreservation of ovarian tissue are considered experimental and should only be offered within the context of a clinical trial. For various reasons, barriers against FP still are high among BC patients, oncologists, and fertility specialists. Early pretreatment consultation for FP with both the oncology team and a fertility specialist are recommended and require an interdisciplinary medical team, in-depth knowledge, and good communication skills.

\section{Acknowledgment}

The authors want to thank Dorothy Huang for her valuable comments and suggestions regarding this paper.

\section{Disclosure}

The authors report no conflicts of interest in this work.

\section{References}

1. Siegel R, Ma J, Zou Z, Jemal A. Cancer statistics, 2014. CA Cancer J Clin. 2014;64(1):9-29.

2. Bland KI, Menck HR, Scott-Conner CE, Morrow M, Winchester DJ, Winchester DP. The National Cancer Data Base 10-year survey of breast carcinoma treatment at hospitals in the United States. Cancer. 1998;83(6):1262-1273.
3. Martin J, Hamilton B, Ventura S, et al. Births: Final data for 2009 . National vital statistics reports. Hyattsville, MD: National Center for Health Statistics; 2011. Available from: http://www.cdc.gov/nchs/data/ nvsr/nvsr60/nvsr60_01.pdf. Accessed May 30, 2014.

4. Martinez GM, Chandra A, Abma JC, Jones J, Mosher WD. Fertility, contraception, and fatherhood: data on men and women from cycle 6 (2002) of the 2002 National Survey of Family Growth. Vital Health Stat. 2006;26:1-142.

5. Schover LR, Rybicki LA, Martin BA, Bringelsen KA. Having children after cancer. A pilot survey of survivors' attitudes and experiences. Cancer. 1999;86(4):697-709.

6. National Cancer Institute. Surveillance, Epidemiology, and End Results Program (SEER). Stat Facts Sheets: Breast cancer. Available from: http://seer.cancer.gov/statfacts/html/breast.html. Accessed May 30, 2014.

7. Canada AL, Schover LR. The psychosocial impact of interrupted childbearing in long-term female cancer survivors. Psychooncology. 2012;21(2):134-143.

8. Ethics Committee of the American Society for Reproductive Medicine. Fertility preservation and reproduction in cancer patients. Fertil Steril. 2005;83(6):1622-1628.

9. Lee SJ, Schover LR, Partridge AH, et al. American Society of Clinical Oncology recommendations on fertility preservation in cancer patients. J Clin Oncol. 2006;24(18):2917-2931.

10. Adams E, Hill E, Watson E. Fertility preservation in cancer survivors: a national survey of oncologists' current knowledge, practice and attitudes. Br J Cancer. 2013;108(8):1602-1615.

11. Lawrenz B, Jauckus J, Kupka MS, Strowitzki T, von Wolff M. Fertility preservation in $>1,000$ patients: patient's characteristics, spectrum, efficacy and risks of applied preservation techniques. Arch Gynecol Obstet. 2011;283(3):651-656.

12. Quinn G, Vadaparampil S, Jacobsen P, et al. National survey of physician practice patterns: fertility preservation and cancer patients. J Clin Oncol. 2009;27(35):5952-5957.

13. Mueller BA, Simon MS, Deapen D, Kamineni A, Malone KE, Daling JR. Childbearing and survival after breast carcinoma in young women. Cancer. 2003;98(6):1131-1140.

14. Azim HA Jr, Santoro L, Pavlidis N, et al. Safety of pregnancy following breast cancer diagnosis: a meta-analysis of 14 studies. Eur J Cancer. 2011;47(1):74-83.

15. Sankila R, Heinavaara S, Hakulinen T. Survival of breast cancer patients after subsequent term pregnancy: "healthy mother effect". Am J Obstet Gynecol. 1994;170(3):818-823.

16. Largillier R, Savignoni A, Gligorov J, et al. Prognostic role of pregnancy occurring before or after treatment of early breast cancer patients aged $<35$ years: a GET(N)A Working Group analysis. Cancer. 2009;115(22):5155-5165.

17. United States. Fertility Clinic Success Rate and Certification Act of 1992: Public Law 102-493. US Statut Large. 1992;106:3146-3152.

18. Committee on Gynecologic Practice of American College of Obstetricians and Gynecologists; Practice Committee of American Society for Reproductive Medicine. Age-related fertility decline: a committee opinion. Fertil Steril. 2008;90(Suppl 5):S154-S155.

19. Tarlatzis BC, Zepiridis L. Perimenopausal conception. Ann N Y Acad Sci. 2003;997:93-104.

20. Centers for Disease Control and Prevention, American Society for Reproductive Medicine, Society for Assisted Reproductive Technology. 2011 Assisted Reproductive Technology Fertility Clinic Success Rates Report. Atlanta, GA, USA: US Dept of Health and Human Services; 2013. Available from: http://www.cdc.gov/art/ART2011/PDFs/ ART_2011_Clinic_Report-Full.pdf. Accessed May 31, 2014.

21. MacDougall K, Beyene Y, Nachtigall RD. Age shock: misperceptions of the impact of age on fertility before and after IVF in women who conceived after age 40. Hum Reprod. 2013;28(2):350-356.

22. Faddy MJ, Gosden RG, Gougeon A, Richardson SJ, Nelson JF. Accelerated disappearance of ovarian follicles in mid-life: implications for forecasting menopause. Hum Reprod. 1992;7(10):1342-1346. 
23. Practice Committee of the American Society for Reproductive Medicine. Testing and interpreting measures of ovarian reserve: a committee opinion. Fertil Steril. 2012;98(6):1407-1415.

24. Broekmans FJ, Kwee J, Hendriks DJ, Mol BW, Lambalk CB. A systematic review of tests predicting ovarian reserve and IVF outcome. Hum Reprod Update. 2006;12(6):685-718.

25. Streuli I, Fraisse T, Chapron C, Bijaoui G, Bischof P, de Ziegler D. Clinical uses of anti-Mullerian hormone assays: pitfalls and promises. Fertil Steril. 2009;91(1):226-230.

26. Rustamov O, Smith A, Roberts SA, et al. Anti-Mullerian hormone: poor assay reproducibility in a large cohort of subjects suggests sample instability. Hum Reprod. 2012;27(10):3085-3091.

27. Anderson RA, Rosendahl M, Kelsey TW, Cameron DA. Pretreatment anti-Mullerian hormone predicts for loss of ovarian function after chemotherapy for early breast cancer. Eur J Cancer. 2013;49(16): 3404-3411.

28. Casadei L, Manicuti C, Puca F, Madrigale A, Emidi E, Piccione E. Can anti-Mullerian hormone be predictive of spontaneous onset of pregnancy in women with unexplained infertility? J Obstet Gynaecol. 2013;33(8):857-861.

29. Broer SL, van Disseldorp J, Broeze KA, et al. Added value of ovarian reserve testing on patient characteristics in the prediction of ovarian response and ongoing pregnancy: an individual patient data approach. Hum Reprod Update. 2013;19(1):26-36.

30. Bines J, Oleske DM, Cobleigh MA. Ovarian function in premenopausal women treated with adjuvant chemotherapy for breast cancer. J Clin Oncol. 1996;14(5):1718-1729.

31. Petrek JA, Naughton MJ, Case LD, et al. Incidence, time course, and determinants of menstrual bleeding after breast cancer treatment: a prospective study. J Clin Oncol. 2006;24(7):1045-1051.

32. Meirow D, Biederman H, Anderson RA, Wallace WH. Toxicity of chemotherapy and radiation on female reproduction. Clin Obstet Gynecol. 2010;53(4):727-739.

33. Morgan S, Anderson RA, Gourley C, Wallace WH, Spears N. How do chemotherapeutic agents damage the ovary? Hum Reprod Update. 2012;18(5):525-535.

34. Rodriguez-Wallberg KA, Oktay K. Fertility preservation and pregnancy in women with and without BRCA mutation-positive breast cancer. Oncologist. 2012;17(11):1409-1417.

35. Sonmezer M, Oktay K. Fertility preservation in young women undergoing breast cancer therapy. Oncologist. 2006;11(5):422-434.

36. Goldhirsch A, Winer EP, Coates AS, et al. Personalizing the treatment of women with early breast cancer: highlights of the St Gallen International Expert Consensus on the Primary Therapy of Early Breast Cancer 2013. Ann Oncol. 2013;24(9):2206-2223.

37. Colleoni M, Rotmensz N, Robertson C, et al. Very young women ( $<35$ years) with operable breast cancer: features of disease at presentation. Ann Oncol. 2002;13(2):273-279.

38. Lewis PE, Sheng M, Rhodes MM, Jackson KE, Schover LR. Psychosocial concerns of young African American breast cancer survivors. J Psychosoc Oncol. 2012;30(2):168-184.

39. Partridge AH, Gelber S, Peppercorn J, et al. Web-based survey of fertility issues in young women with breast cancer. J Clin Oncol. 2004; 22(20):4174-4183.

40. Schover LR. Patient attitudes toward fertility preservation. Pediatr Blood Cancer. 2009;53(2):281-284.

41. Letourneau JM, Ebbel EE, Katz PP, et al. Pretreatment fertility counseling and fertility preservation improve quality of life in reproductive age women with cancer. Cancer. 2012;118(6):1710-1717.

42. Klemp JR, Kim SS. Fertility preservation in young women with breast cancer. J Assist Reprod Genet. 2012;29(6):469-472.

43. Tschudin S, Bitzer J. Psychological aspects of fertility preservation in men and women affected by cancer and other life-threatening diseases. Hum Reprod Update. 2009;15(5):587-597.

44. Garvelink MM, ter Kuile MM, Fischer MJ, et al. Development of a decision aid about fertility preservation for women with breast cancer in The Netherlands. J Psychosom Obstet Gynaecol. 2013;34(4):170-178.
45. Peate M, Meiser B, Cheah BC, et al. Making hard choices easier: a prospective, multicentre study to assess the efficacy of a fertilityrelated decision aid in young women with early-stage breast cancer. Br J Cancer. 2012;106(6):1053-1061.

46. Bedoschi G, Oktay K. Current approach to fertility preservation by embryo cryopreservation. Fertil Steril. 2013;99(6):1496-1502.

47. Practice Committees of American Society for Reproductive Medicine; Society for Assisted Reproductive Technology. Mature oocyte cryopreservation: a guideline. Fertil Steril. 2013;99(1):37-43.

48. [No authors listed]. ACOG: Committee Opinion No 584: oocyte cryopreservation. Obstet Gynecol. 2014;123(1):221-222.

49. Bedoschi G, Turan V, Oktay K. Utility of GnRH-agonists for fertility preservation in women with operable breast cancer: is it protective? Curr Breast Cancer Rep. 2013;5(4):302-308.

50. Loren AW, Mangu PB, Beck LN, et al. Fertility preservation for patients with cancer: American Society of Clinical Oncology clinical practice guideline update. J Clin Oncol. 2013;31(19):2500-2510.

51. Barcroft J, Dayoub N, Thong KJ. Fifteen year follow-up of embryos cryopreserved in cancer patients for fertility preservation. $J$ Assist Reprod Genet. 2013;30(11):1407-1413.

52. Lee S, Ozkavukcu S, Heytens E, Moy F, Oktay K. Value of early referral to fertility preservation in young women with breast cancer. $J$ Clin Oncol. 2010;28(31):4683-4686.

53. Kim J, Kim KH, Mersereau JE. Building a successful fertility preservation program at a major cancer center. J Gynecol Oncol. 2014;25(2): $148-154$.

54. Noyes N, Melzer K, Druckenmiller S, Fino ME, Smith M, Knopman JM. Experiences in fertility preservation: lessons learned to ensure that fertility and reproductive autonomy remain options for cancer survivors. J Assist Reprod Genet. 2013;30(10):1263-1270.

55. Sagi M, Weinberg N, Eilat A, et al. Preimplantation genetic diagnosis for BRCA1/2 - a novel clinical experience. Prenat Diagn. 2009;29(5): 508-513.

56. Practice Committee of American Society for Reproductive Medicine. Fertility preservation in patients undergoing gonadotoxic therapy or gonadectomy: a committee opinion. Fertil Steril. 2013;100(5): 1214-1223.

57. Ayensu-Coker L, Essig E, Breech LL, Lindheim S. Ethical quandaries in gamete-embryo cryopreservation related to oncofertility. J Law Med Ethics. 2013;41(3):711-719.

58. Campo-Engelstein L. Consistency in insurance coverage for iatrogenic conditions resulting from cancer treatment including fertility preservation. J Clin Oncol. 2010;28(8):1284-1286.

59. Shah DK, Goldman E, Fisseha S. Medical, ethical, and legal considerations in fertility preservation. Int J Gynaecol Obstet. 2011;115(1):11-15.

60. Cakmak H, Katz A, Cedars MI, Rosen MP. Effective method for emergency fertility preservation: random-start controlled ovarian stimulation. Fertil Steril. 2013;100(6):1673-1680.

61. Sonmezer M, Turkcuoglu I, Coskun U, Oktay K. Random-start controlled ovarian hyperstimulation for emergency fertility preservation in letrozole cycles. Fertil Steril. 2011;95(6):2125. e9-e11.

62. Madrigrano A, Westphal L, Wapnir I. Egg retrieval with cryopreservation does not delay breast cancer treatment. Am J Surg. 2007;194(4): 477-481.

63. de Ziegler D, Streuli I, Vasilopoulos I, Decanter C, This P, Chapron C. Cancer and fecundity issues mandate a multidisciplinary approach. Fertil Steril. 2010;93(3):691-696.

64. Olivennes F, Fanchin R, Bouchard P, Taieb J, Frydman R. Triggering of ovulation by a gonadotropin-releasing hormone $(\mathrm{GnRH})$ agonist in patients pretreated with a GnRH antagonist. Fertil Steril. 1996;66(1): $151-153$.

65. Humaidan P, Kol S, Papanikolaou EG. GnRH agonist for triggering of final oocyte maturation: time for a change of practice? Hum Reprod Update. 2011;17(4):510-524.

66. Tang H, Hunter T, Hu Y, Zhai SD, Sheng X, Hart RJ. Cabergoline for preventing ovarian hyperstimulation syndrome. Cochrane Database Syst Rev. 2012;2:CD008605. 
67. Mozes M, Bogokowsky H, Antebi E, et al. Thromboembolic phenomena after ovarian stimulation with human gonadotrophins. Lancet. 1965;2(7424):1213-1215.

68. Dahhan T, Balkenende E, van Wely M, Linn S, Goddijn M. Tamoxifen or letrozole versus standard methods for women with estrogen-receptor positive breast cancer undergoing oocyte or embryo cryopreservation in assisted reproduction. Cochrane Database Syst Rev. 2013;11: CD010240.

69. Martinez-Burgos M, Herrero L, Megias D, et al. Vitrification versus slow freezing of oocytes: effects on morphologic appearance, meiotic spindle configuration, and DNA damage. Fertil Steril. 2011;95(1):374-377.

70. Kuwayama M, Vajta G, Kato O, Leibo SP. Highly efficient vitrification method for cryopreservation of human oocytes. Reprod Biomed Online. 2005;11(3):300-308.

71. Oktay K, Cil AP, Bang H. Efficiency of oocyte cryopreservation: a meta-analysis. Fertil Steril. 2006;86(1):70-80.

72. Cil AP, Bang H, Oktay K. Age-specific probability of live birth with oocyte cryopreservation: an individual patient data meta-analysis. Fertil Steril. 2013;100(2):492-499. e3.

73. Domingo J, Guillen V, Ayllon Y, et al. Ovarian response to controlled ovarian hyperstimulation in cancer patients is diminished even before oncological treatment. Fertil Steril. 2012;97(4):930-934.

74. Kim SS, Donnez J, Barri P, et al. Recommendations for fertility preservation in patients with lymphoma, leukemia, and breast cancer. $J$ Assist Reprod Genet. 2012;29(6):465-468.

75. Raffi F, Metwally M, Amer S. The impact of excision of ovarian endometrioma on ovarian reserve: a systematic review and meta-analysis. J Clin Endocrinol Metab. 2012;97(9):3146-3154.

76. Donnez J, Dolmans MM, Pellicer A, et al. Restoration of ovarian activity and pregnancy after transplantation of cryopreserved ovarian tissue: a review of 60 cases of reimplantation. Fertil Steril. 2013;99(6):1503-1513.

77. Kim SS. Revisiting the role of heterotopic ovarian transplantation: futility or fertility. Reprod Biomed Online. 2014;28(2):141-145.

78. Oktay K. Spontaneous conceptions and live birth after heterotopic ovarian transplantation: is there a germline stem cell connection? Hum Reprod. 2006;21(6):1345-1348.

79. Rabban JT, Barnes M, Chen LM, Powell CB, Crawford B, Zaloudek CJ Ovarian pathology in risk-reducing salpingo-oophorectomies from women with BRCA mutations, emphasizing the differential diagnosis of occult primary and metastatic carcinoma. Am J Surg Pathol. 2009;33(8):1125-1136.

80. Practice Committee of the American Society for Reproductive Medicine. Ovarian tissue cryopreservation: a committee opinion. Fertil Steril. 2014;101(5):1237-1243.

81. Berwanger AL, Finet A, El Hachem H, le Parco S, Hesters L, Grynberg M. New trends in female fertility preservation: in vitro maturation of oocytes. Future Oncol. 2012;8(12):1567-1573.

82. Huang JY, Tulandi T, Holzer H, Tan SL, Chian RC. Combining ovarian tissue cryobanking with retrieval of immature oocytes followed by in vitro maturation and vitrification: an additional strategy of fertility preservation. Fertil Steril. 2008;89(3):567-572.

83. Chian RC, Huang JY, Gilbert L, et al. Obstetric outcomes following vitrification of in vitro and in vivo matured oocytes. Fertil Steril. 2009; 91(6):2391-2398.

84. Ronn R, Holzer HE. Oncofertility in Canada: cryopreservation and alternative options for future parenthood. Curr Oncol. 2014;21(1):e137-e146.

Breast Cancer: Targets and Therapy

\section{Publish your work in this journal}

Breast Cancer: Targets and Therapy is an international, peerreviewed open access journal focusing on breast cancer research, identification of therapeutic targets and the optimal use of preventative and integrated treatment interventions to achieve improved outcomes, enhanced survival and quality of life for the cancer patient.
85. Practice Committees of the American Society for Reproductive Medicine and the Society for Assisted Reproductive Technology. In vitro maturation: a committee opinion. Fertil Steril. 2013;99(3):663-666.

86. Turner NH, Partridge A, Sanna G, Di Leo A, Biganzoli L. Utility of gonadotropin-releasing hormone agonists for fertility preservation in young breast cancer patients: the benefit remains uncertain. Ann Oncol. 2013;24(9):2224-2235.

87. Partridge AH, Gelber S, Peppercorn J, et al. Fertility and menopausal outcomes in young breast cancer survivors. Clin Breast Cancer. 2008;8(1):65-69.

88. Chandra A, Stephen EH. Infertility service use among US women: 1995 and 2002. Fertil Steril. 2010;93(3):725-736.

89. Moffat R, de Geyter C, Myrick ME, et al. Young women with breast cancer: how many are actually candidates for fertility preservation? Arch Gynecol Obstet. 2012;286(6):1521-1527.

90. Baxter NN, Sutradhar R, DelGuidice ME, et al. A population-based study of rates of childbirth in recurrence-free female young adult survivors of non-gynecologic malignancies. BMC Cancer. 2013;13:30.

91. Cvancarova M, Samuelsen SO, Magelssen H, Fossa SD. Reproduction rates after cancer treatment: experience from the Norwegian radium hospital. J Clin Oncol. 2009;27(3):334-343.

92. Goncalves V, Sehovic I, Quinn G. Childbearing attitudes and decisions of young breast cancer survivors: a systematic review. Hum Reprod Update. 2014;20(2):279-292.

93. Kellerman SE, Herold J. Physician response to surveys. A review of the literature. Am J Prev Med. 2001;20(1):61-67.

94. Shimizu C, Bando H, Kato T, Mizota Y, Yamamoto S, Fujiwara Y. Physicians' knowledge, attitude, and behavior regarding fertility issues for young breast cancer patients: a national survey for breast care specialists. Breast Cancer. 2013;20(3):230-240.

95. King JW, Davies MC, Roche N, Abraham JM, Jones AL. Fertility preservation in women undergoing treatment for breast cancer in the UK: a questionnaire study. Oncologist. 2012;17(7):910-916.

96. Shimizu C, Kato T, Tamura N, et al. Perception and needs of reproductive specialists with regard to fertility preservation of young breast cancer patients. Int J Clin Oncol. February 22, 2014. [Epub ahead of print.]

97. Goossens J, Delbaere I, Van Lancker A, Beeckman D, Verhaeghe S, Van Hecke A. Cancer patients' and professional caregivers' needs, preferences and factors associated with receiving and providing fertility-related information: a mixed-methods systematic review. Int J Nurs Stud. 2014;51(2):300-319.

98. Niemasik EE, Letourneau J, Dohan D, et al. Patient perceptions of reproductive health counseling at the time of cancer diagnosis: a qualitative study of female California cancer survivors. $J$ Cancer Surviv. 2012;6(3):324-332.

99. Yee S, Abrol K, McDonald M, Tonelli M, Liu KE. Addressing oncofertility needs: views of female cancer patients in fertility preservation. J Psychosoc Oncol. 2012;30(3):331-346.

100. Ruddy KJ, Gelber SI, Tamimi RM, et al. Prospective study of fertility concerns and preservation strategies in young women with breast cancer. J Clin Oncol. 2014;32(11):1151-1156.

101. Lee S, Heytens E, Moy F, Ozkavukcu S, Oktay K. Determinants of access to fertility preservation in women with breast cancer. Fertil Steril. 2011;95(6):1932-1936.

102. Letourneau JM, Smith JF, Ebbel EE, et al. Racial, socioeconomic, and demographic disparities in access to fertility preservation in young women diagnosed with cancer. Cancer. 2012;118(18):4579-4588.

\section{Dovepress}

View the full aims and scopes of this journal here. The manuscript management system is completely online and includes a very quick and fair peer-review system, which is all easy to use. Visit http:// www.dovepress.com/testimonials.php to read real quotes from published authors. 